\title{
UM ESTUDO À LUZ DA RELAÇÃO ENTRE ADMINISTRAÇÃO PÚBLICA E PARTICIPAÇÃO POPULAR: POSSIBILIDADES E DESAFIOS DO ESTADO DEMOCRÁTICO DE DIREITO
}

A Study in the Light of the Relationship between Public Administration and Popular Participation:

Possibilities and Challenges of the Democratic Rule of Law

Un Estudio a la Luz de la Relación entre la administración pública y la participación popular: posibilidades y desafíos del estado de derecho democrático

Received: july/2020

Accepted: september $/ 2020$

Available online: september/2020

Maycon Anderson do Valle Freitas, Bacharel em Administração Pública, Universidade Federal de São João del-Rei - UFSJ, Brasil. E-mail: maycon.ufsj@yahoo.com.br

Pablo Luiz Martins, Doutor em Ciências da Linguagem, Universidade Federal de São João del-Rei - UFSJ, Brasil. E-mail: pablo@ufsj.edu.br

Franciane de Oliveira Alvarenga, Doutora em Ciências Contábeis, Universidade Federal de São João del-Rei - UFSJ, Brasil. E-mail: francianealvarenga@ufsj.edu.br

\footnotetext{
Resumo: Neste trabalho levantaremos questões referente a Participação Popular e sua relação com a Administração Pública, seu histórico, desenvolvimento e possibilidades. Enquanto objetivo geral, buscamos debater sobre os institutos jurídicos que asseguram a participação popular na Administração Pública, mas não somente de doutrina jurídica, mas multidisciplinar, com lócus voltado às discussões da ciência administrativa, ciência política e sociológica. No plano da Administração Pública, verifica-se a criação de novas formas de atuação, inspiradas no postulado da democracia participativa, que alteram a relação não só com os administrados, mas também com seus próprios agentes e com sua estrutura hierárquica. Buscaremos uma abordagem que conceitualize, procedimente e trace diretrizes e discussões em um plano geral de elaboração de uma boa revisão de literatura. Por fim podemos verificar que a participação popular no âmbito da Administração Pública pode promover uma estruturação democrática por meio de processos que envolvem diálogos e decisões mútuas, visando assim o aumento no nível de eficiência e eficácia dos serviços por ela prestados, ampliando as dimensões do Bem-Estar coletivo e justiça social e transparência da própria atuação na administração dos recursos de cunho político, econômico e social.
}

Palavras-chave: Administração Pública, Estado Democrático de Direito, Participação Popular, Novas Possibilidades, Justiça Social. 


\begin{abstract}
In this work, we will raise questions regarding Popular Participation and its relationship with Public Administration, its history, development and possibilities. As a general objective, we seek to debate the legal institutes that ensure popular participation in Public Administration, but not only of legal doctrine, but multidisciplinary, with a focus on discussions of administrative science, political and sociological science. At the level of Public Administration, there is a creation of new forms of action, inspired by the postulate of participatory democracy, which alter the relationship not only with the administrated, but also with their own agents and with their hierarchical structure. We will look for an approach that conceptualizes, proceeds and traces guidelines and discussions in a general plan for preparing a good literature review. Finally, we can see that popular participation in the scope of Public Administration can promote a democratic structuring through processes that involve dialogues and mutual decisions, thus aiming at increasing the level of efficiency and effectiveness of the services provided by it, expanding the dimensions of the Good -Being collective and social justice and transparency of its own performance in the administration of resources of a political, economic and social nature.
\end{abstract}

Keywords: Public Administration, Democratic Rule of Law, Popular Participation, New Possibilities, Social Justice.

Resumen: En este trabajo, plantearemos preguntas sobre la participación popular y su relación con la administración pública, su historia, desarrollo y posibilidades. Como objetivo general, buscamos debatir los institutos legales que aseguran la participación popular en la Administración Pública, pero no solo de doctrina legal, sino multidisciplinaria, con un enfoque en las discusiones de ciencias administrativas, ciencias políticas y sociológicas. A nivel de la Administración Pública, se crean nuevas formas de acción, inspiradas en el postulado de la democracia participativa, que alteran la relación no solo con los administrados, sino también con sus propios agentes y con su estructura jerárquica. Buscaremos un enfoque que conceptualice, proceda y rastree pautas y discusiones en un plan general para preparar una buena revisión de la literatura. Finalmente, podemos ver que la participación popular en el ámbito de la Administración Pública puede promover una estructuración democrática a través de procesos que involucren diálogos y decisiones mutuas, con el objetivo de aumentar el nivel de eficiencia y eficacia de los servicios que presta, ampliando las dimensiones del Bien. -Ser justicia colectiva y social y transparencia de su desempeño en la administración de recursos de carácter político, económico y social.

Palabras clave: Administración Pública, Estado de derecho Democrático, Participación Popular, Nuevas Posibilidades, Justicia Social.

\title{
1. INTRODUÇÃO
}

A participação, enquanto atividade intrínseca à política dos cidadãos constitui-se como uma das prerrogativas do Estado Democrático de Direito (DALLARI, 1995). Cabe ressaltar que pode ser considerado democrático o Estado onde participam os cidadãos no poder, mesmo se for de maneira simples e que não garanta a existência de democracia, frente a imprescindibilidade de outros requisitos, como: igualdade, legalidade, pluralidade, respeito às minorias entre outros (PEREZ, 2004).

Essa participação pode adentrar no exercício das funções estatais, seja no âmbito legislativo, jurisdicional e/ou administrativo. Esta última, aprofundaremos enquanto objeto de pesquisa. 
Apresentamos como objetivo deste trabalho, não somente o estudo dos instrumentos jurisdicionais e/ou legislativos que possibilitem ao cidadão a participar do exercício dessas respectivas funções, ainda que visem ao controle dos atos da Administração Pública, como ocorre, por exemplo, com as petições em relações às comissões legislativas contra ato de autoridade administrativa, ou no caso da ação popular e do mandado de segurança. Apresentamos uma releitura de autores que apresentam novas possibilidades dentro de participação popular na Administração Pública.

Ainda que esses institutos jurídicos se coloquem, em sentido amplo, como instrumentos participativos de controle da Administração Pública, sua abordagem, no presente trabalho, deslocaria excessivamente o seu eixo central que, freze, encontra-se na sondagem dos institutos administrativos de participação popular no exercício da função administrativa do Estado (BOBBIO, 1996).

Existem três fatores que podem nos direcionar para o desenvolvimento de pensamentos que são determinantes na atualidade devido sua importância em termos de reflexão do que já fora produzido sobre o assunto. O primeiro motivo depreende-se da evidente imbricação do debate da participação popular na Administração Pública com o debate da democratização do Estado e de suas relações sociais, cuja a atualidade é incontestável (BOBBIO, 1996).

O segundo motivo está explanado na experiência já desenvolvida pela área do Direito, que perpassa a aplicação dos muitos institutos jurídicos de participação popular na Administração Pública existentes na legislação brasileira, às quais nos fornecem referencial teórico plausível para estudo. Dessa forma, estamos movidos pela ânsia de discutir a natureza jurídica e o modo como funcionam tais institutos, de maneira a auxiliar-nos na interpretação correta dos mesmos. 
Já como terceiro fator e que é considerado o mais "polêmico" de todos, revela-se a partir da convergência dos escopos dos institutos de participação popular na Administração Pública com aqueles buscados pela(s) reforma(s) administrativa(s) no Brasil. (BOBBIO, 1996).

De acordo com Brasil (1998) a Emenda Constitucional (EC) No 19, buscou promover no Brasil um projeto de reforma administrativa e modernização do Estado. Os desígnios dessa reforma vinham expostos de forma genérica no documento divulgado pela Presidência da República com o título de "Plano Diretor da Reforma do Aparelho do Estado".

Tais desígnios não se distanciavam daqueles buscados, hoje, pela Administração Pública, mundialmente falando: - maior eficiência no desempenho das atividades da administração; - maior agilidade e capacidade gerencial; - maior legitimidade e transparência; - maior aproximação com a sociedade, seja por meio do cultivo de formas de colaboração ou parceria, seja por meio da instituição de novas formas de controle de qualidade de atuação administrativa (PEREZ, 2004).

Na realidade, tais objetivos constituem, na atualidade, o norte da Administração Pública, tendo em vista o ambiente de crítica e de reavaliação que em torno desta foi criado nos últimos 20 anos do século passado, mas não somente no Brasil, como também em todo o resto do mundo.

Enquanto objetivo geral, buscamos debater sobre os institutos jurídicos que asseguram a participação popular na Administração Pública, mas não somente de doutrina jurídica, mas multidisciplinar, com lócus voltado às discussões da ciência administrativa, ciência política e sociológica.

Já enquanto objetivos específicos almejamos: 1- Analisar as razões que fundamentam a existência dos institutos de participação popular na Administração Pública; 2- Discutir como se encontram inseridos esses institutos no âmbito do sistema jurídico brasileiro; 3- Detalhar as características, aspectos mais polêmicos e problemas relacionados ao desenvolvimento de tais institutos. 
Neste trabalho apresentamos uma abordagem que conceitualize, procedimente e trace diretrizes e discussões em um plano geral de elaboração de uma boa revisão de literatura.

\section{O DESENVOLVIMENTO DA DEMOCRACIA PARTICIPATIVA}

Em que pese a existência da "Democracia Ateniense" e a constatação de que o debate em torno das ideias democráticas remonta aos filósofos gregos da antiguidade clássica (SARTORI, 2004), o Estado democrático, tal como o entendemos hoje, é fruto das revoluções liberais do final do século XVIII e de seu posterior desenvolvimento.

É evidente, que a veiculação das ideias democráticas pela burguesia liberal da referida época prendia-se à intenção de derrubada do absolutismo. Era a democracia, nesse primeiro momento, menos um conjunto de ideias pronto e acabado de organização do Estado e mais um “grito de guerra" contra o poder exercido de maneira arbitrária e autocrática (SARTORI, 2004).

Deve-se ao século XIX o aperfeiçoamento da "teoria da democracia”. É nesse momento que se consagra o modelo democrático da era moderna, a democracia representativa, que passa, então, mediante os seus princípios ideológicos, como por exemplo: Rousseau, Madison, Betham, Mill, Dalh, Denhart entre outros, a ser concebido como regime ideal para a proteção da liberdade em face do arbítrio do Estado (HELD, 1997).

Desde então, o governo democrático vem sendo associado à máxima quase enigmática de Lincoln do "governo do povo, pelo povo e para o povo" (LINCOLN, 2001, p. 103), e, mais especificamente, aos princípios liberais de proteção do indivíduo contra o abuso do poder estatal.

Reconhece-se, desde então, como democrático o governo que preserva as liberdades públicas, direitos fundamentais individuais como a liberdade de locomoção, de comércio, de pensamento e expressão; o governo que evita a concentração de poderes por meio da adoção do princípio da separação de poderes; o governo submetido à lei e legitimado pela realização periódica 
de eleições, momento em que o "povo" exprimiria sua "vontade suprema" e delegaria aos seus mandatários o poder de governá-los por determinado período (PEREZ, 2004).

Entretanto, todos sabem que, durante o século XIX o debate em torno desse ideário e, principalmente, a sua aplicação não foram nada pacíficos. Incessantes foram os conflitos, ora por reação das monarquias que tiveram seu poder confiscado, ora por pressão do proletariado que se formava nos centros urbanos (classe submetida a condições de vida absolutamente degradantes e sem direito de votar nas eleições), ora por resistência da burguesia que, tendo ascendido à condição de classe dominante, se consolidava no poder do Estado e portava-se dubiamente, como liberal no plano econômico, mas autocrática no plano político e social.

Dahl (1994) entende a democracia em duas dimensões: contestação pública e inclusividade. O desenvolvimento destas duas dimensões Dahl deu o nome de Democratização. O direito a votar em eleições livres está implícito nas duas dimensões, pois

[...] tal direito estimula a contestação pública e ao mesmo tempo torna o regime inclusivo com a proporção significativa de pessoas votantes. Assim, contestação pública e inclusividade transformam-se em dois critérios para a classificação dos regimes políticos. Quando regimes hegemônicos - de precária contestação e inclusividade - caminham em direção a uma poliarquia, indica que aumentaram as possibilidades de efetiva contestação e inclusão (SILVA, 2008, p. 1).

De qualquer modo, as ideias democráticas prevaleceram e o Estado Democrático desenvolveu-se em meio a todos esses conflitos sociais e, até mesmo, em razão da pressão deles advinda. A chamada democracia representativa e liberal fortalece-se e atingiu o ápice de seu prestígio entre o final do século XIX e o início do século XX em razão principalmente, da gradativa universalização do sufrágio (CANOTILHO, 2003).

A ampliação da democracia representativa conduziria a uma profunda mudança no perfil do Estado. Ela impulsionou o exercício das liberdades públicas e, sob pressão dos eleitores, foram consagrados os direitos sociais, direitos fundamentais de segunda geração (FERREIRA FILHO, 
2005). A partir de então, o Estado passou a ingerir em todo o tecido social, regulando relações de toda a natureza (CHEVALLIER, 2008; MEDAUAR, 1996).

Essa renovada democracia, proveniente da massificação do sufrágio e do reconhecimento dos direitos fundamentais sociais, tornada norma jurídica pela fórmula da Constituição Alemã de Weimar (SCHMITT, 2003), continuava fiel, no plano político, ao modelo puramente representativo. Não era nada incomum que constitucionalistas do maior quilate, muito embora afirmassem que o princípio democrático implicasse a manutenção de uma relação direta entre o governo e o povo, se opuseram às inovações democratizantes, especialmente com relação à atuação da Administração Pública (CANOTILHO, 2003).

A democracia passa então a tentar conciliar intervencionismo estatal, no plano socioeconômico, com liberalismo, no plano político jurídico. Melhor dizendo, pretende-se que o Estado passe a realizar políticas sociais e impulsionar a economia, mas se espera que os instrumentos liberais de contenção do poder do Estado sejam suficientes para continuar a coibir o arbítrio.

Esse modelo demora muito para se firmar. Os inúmeros regimes autocráticos da primeira metade do século XX (com destaque para os genocidas nazista, fascista e stalinista) e o advento de duas grandes guerras mundiais sufocaram a hegemonia da democracia.

No Brasil, muito embora proclamada a República, desde a virada do século XIX, o coronelismo, o clientelismo, a fraude costumeira das eleições e a ditadura de Getúlio Vargas também não foram capazes de nos dar um governo verdadeiramente democrático (BENEVIDES, 2006).

Como salienta Held (2007, p. 201), o clima do pós-guerra “[...] parece ter gerado uma maré de promessas e esperanças por uma nova era marcada por progressivas mudanças nas relações entre o Estado e sociedade". Silva (2010) também descreve esses fatos, narrando o desenvolvimento 
histórico do Estado pela passagem do Estado de Direito para o Estado Social de direito e, em seguida, para o Estado Democrático de Direito. Habermas (2012) confirma que a existência e a manutenção do Estado de Direito estão atualmente associadas à radicalização da democracia.

Mas a contradição entre intervencionismo econômico-social e liberalismo político-jurídico continuava subjacente à ordem democrática do pós-guerra.

Segundo Ferreira Filho (2002) não demorou muito para que a ciência política viesse diagnosticar os problemas vivenciados pela democracia representativa:

1- oligarquização dos partidos políticos;

2- excessiva profissionalização da política;

3- desinteresse dos eleitores pela participação política;

4- incapacidade dos parlamentares para identificar e resolver os complexos problemas inerentes à atuação estatal no domínio social e econômico;

5- falta de educação política dos eleitores, levando-os a optar mais emotiva do que racionalmente, no momento de escolha dos governantes;

6- dificuldade de contenção do abuso do poder econômico nas eleições;

7- influência nociva dos meios de comunicação de massas (SARTORI, 2004);

8- personalização excessiva do processo eleitoral;

9- desprestígio da lei enquanto instrumento normativo;

10- concentração de poderes nas mãos da burocracia do Executivo;

11- cerceamento do debate parlamentar mediante a edição de atos normativos com força de lei pelo Executivo. 
Em que pese não se ter encontrado, até o momento, uma fórmula apta a resolver definitivamente todos esses problemas, uma das soluções encontradas pelas Constituições editadas ou reformadas a partir da década de 70 (Constituição portuguesa de 1976, Constituição espanhola de 1978, Constituição brasileira de 1988, dentre outras) foi a adoção da democracia participativa ou, como alguns preferem dizer, da democracia semidireta como princípio de estruturação do Estado (PEREZ, 2004).

Vê-se, enfaticamente que o desenvolvimento da democracia participativa trouxe grandes impactos diante os aspectos políticos, econômicos e democráticos sob à égide da jurisprudência contemporânea provocando novos embates e novas discussões sobre a estruturação de um Estado mais aberto a participação popular.

\section{A DEMOCRACIA PARTICIPATIVA}

Com essa inovação não se verificou, de fato, o abandono completo do modelo democrático liberal, ou seja, da democracia representativa. A manutenção da maior parte do instrumental democrático liberal, segundo Bobbio (1996), demonstrou-se um pressuposto para a efetivação de um regime verdadeiramente democrático.

O que muito se percebe é que a democracia participativa emerge face aos problemas enfrentados pela democracia representativa para reforçar os controles sobre a atuação estatal (BOBBIO, 1996).

Como revela seu próprio nome, a democracia participativa baseia-se na abertura do Estado a uma participação popular maior do que se admitia no sistema da democracia puramente representativa. No entanto, a democracia participativa conta com vários instrumentos institucionais que, até certo ponto, são novos (iniciativa popular de leis e referendos), que importam na modificação do modo de atuação de todos os poderes estatais e na alteração do relacionamento Estado-sociedade (PEREZ, 2004). 
Se a adoção, pelos ordenamentos constitucionais, dos institutos jurídicos da democracia participativa é recente, o mesmo não se pode dizer de sua concepção teórica. A democracia participativa foi, em verdade, revisitada no intuito de resolver os impasses do sistema representativo, pois faz parte de uma tradição antiga que remonta à Comuna de Paris, ao anarquismo, ao socialismo utópico e, até mesmo à democracia ateniense (BOBBIO, 1996).

O que se pode perceber, é que em nenhum momento, como os dias de hoje, a participação popular foi colocada em tão grande ápice na ordem dos pré-requisitos para a efetiva realização da democracia.

Dessa forma, estamos fazendo referência a uma participação ativa do cidadão, participação vista como "tomar parte pessoalmente" (SARTORI, 2004, p. 159), como vontade ativa, predeterminada, consciente ou, porque não dizer, cívica.

Tal consideração é abstraída de diversos autores renomados, como por exemplo Rawls (2006) que entende como sendo um dos fundamentos da liberdade o fato de os cidadãos intervirem na criação das instituições sociais em nome de seus "interesses superiores" (interesse público) e de seus fins últimos. Os cidadãos são, nessa medida, "fontes autônomas de reivindicações fundadas", ou melhor, são participantes ativos da vida política para que se preserve a continuidade da democracia (RAWS, 2006, p. 356).

Burdeauet al (2005) classifica as formas de governo segundo critérios de participação, identificando dois tipos de governo: o democrático e o autocrático - o primeiro é caracterizado pela autonomia, participação dos indivíduos na produção do Direito e o segundo pela heteronomia (não participação dos indivíduos na produção do Direito).

Ferreira Filho (2002) salienta que a intensificação da participação popular é fator fundamental para a conservação da democracia, bem como para sua efetividade, reconhecendo as limitações do sufrágio. 
O voto é sem dúvida, uma das manifestações da participação popular que reclama a Democracia. Essa participação, contudo, não pode ser resumida ao rito do voto, portanto não deve ser medida em termos de extensão do direito do voto e de elegibilidade. Tem ela outro parâmetro, seguramente mais significativo - a intensidade dessa participação. Não é por mera coincidência que nos países considerados mais democráticos fervilham as associações cívicas, e é grande a preocupação do cidadão com o que é comum a todos, com a "res publica". Só a participação intensa fortalece a Democracia, o rito do voto pode muita vez apenas travesti-la (FERREIRA FILHO, 2002, p. 55).

Para Silva (2010) a democracia participativa está definitivamente ligada ao chamado Estado Democrático de Direito:

A Democracia que o Estado Democrático de Direito realiza há de ser um processo de convivência social numa sociedade livre, justa e solidária (art. $3^{\circ}$, II), em que o poder emana do povo, que deve ser exercido em proveito do povo, diretamente ou por representantes eleitos (art. $1^{\circ}$, parágrafo único); participativa, porque envolve a participação crescente do povo no processo decisório e na formação dos atos do governo; pluralista, porque respeita a pluralidade de ideias, culturas e etnias e pressupõe sociedade; há de ser um processo de libertação da pessoa humana das formas de opressão que não depende apenas do reconhecimento formal de certos direitos individuais, políticos e sociais, mas especificamente da vigência de condições econômicas suscetíveis de favorecer o seu pleno exercício.

Para Dallari (2005), a participação política ativa é um dos pressupostos da vida social democrática e configura-se como um dever inerente à cidadania.

Enfim, é possível dizer que decorre atualmente da democracia, tal como regulada na Constituição brasileira de 1988 e em diversas outras constituições, um verdadeiro princípio jurídico, o princípio da participação (SILVA, 2010), que passa a ser encarado como pré-requisito da perfeita concretização da ordem democrática.

\section{A ATUAL DEMOCRACIA E PARTICIPAÇÃO NA ADMINISTRAÇÃO PÚBLICA}

É necessário destacar que na democracia, na atualidade, existe a preocupação com a realização do que é denominado status active civitatis, ou seja, a democracia atual busca a plena realização dos direitos políticos de "[...] interferência das pessoas na própria atividade do Estado, na formação de sua vontade" (MIRANDA, 2003, p. 107).

Não se pode certificar que esse modelo virá a se tornar definitivo ou mesmo mundialmente hegemônico considerando-se o ritmo com que se operam atualmente as mudanças sociais. No entanto, é certo que as democracias participativas têm revelado grande vitalidade, 
combinando os tradicionais institutos da democracia representativa com outros de democracia semidireta (BURDEAU, 2005, p. 132).

Há de se ressaltar que a participação infiltra-se no exercício de todas as funções do Estado. O Legislativo abre ao referendo, ao plebiscito e à iniciativa popular de leis, devendo contar também com a colaboração dos cidadãos no exercício da fiscalização do Executivo. O Judiciário conta com diversos instrumentos participativos tais como as ações populares, os mandados de segurança coletivos, dentre outros. Dessa forma, a Administração Pública, conta com o administrado para o exercício de funções decisórias, consultivas ou de controle (PEREZ, 2004).

Ou seja, nenhum poder e nenhuma função estatal restam intocáveis à participação popular, posto que feriria o princípio informativo do Estado Democrático de Direito.

Percebemos, então, que o desenvolvimento democrático refletido na constitucionalização da democracia participativa, constitui-se como uma das razões que alicerçam a institucionalização da participação popular nas decisões e no controle da Administração Pública (PEREZ, 2004).

Segundo Canotilho (2003) a democracia é um princípio normativo que não tem somente a função informativa do Estado, mas também um princípio de organização que implica na estruturação de processos que ofereçam aos cidadãos efetivas possibilidades de aprender a democracia, a participar nos processos de decisão, exercer criticidade na divergência de opiniões, produzindo input político-democrático.

Constitucionalmente, está estabelecido aos cidadãos “enquanto administrados [...] específicos direitos de participação no exercício de função administrativa de Estado - 'maxime' quando estejam em causa direitos econômicos, sociais e culturais - e na relevância de grupos de decisão a nível de Estado" (MIRANDA, 2003, p. 346). Porém, não se objetiva, portanto, que o Estado continue a adotar solitariamente, mas que conte com a colaboração de 'entidades da sociedade civil, entidades que importem-na "efetivação de direitos econômicos, sociais e culturais" (CANOTILHO, 2003, p. 393). 
No plano da Administração Pública, verifica-se à criação de novas formas de atuação, inspiradas no postulado da democracia participativa, que alteram a relação da Administração não só com os administrados, mas também com seus próprios agentes e com sua estrutura hierárquica.

Segundo Perez (2004) e Medauar (2006), podemos então falar sobre a democracia no sentido de "democracia de funcionamento", ou seja, da adoção de instrumentos que interferem no modo de atuar da Administração, de maneira a torná-la mais aberta à influência externa ou aos inputs dos administrados, mais responsiva.

Para a eminente administrativista brasileira na presente fase do desenvolvimento democrático a participação do particular se dá mediante a atuação do particular diretamente na gestão e no controle da Administração Pública, tornando-se, assim, uma caraterística essencial do Estado de Direito Democrático, posto que aproxima mais o administrado da Administração, diminuindo ainda mais as barreiras entre o Estado e a sociedade (DI PIETRO, 2003).

Deste modo, diante de todas as observações até o presente momento, é salutar de se inferir que os institutos jurídicos que servem de instrumento à participação popular na Administração Pública encontram amparo político na democracia participativa, ou melhor, justifica a adoção pelo ordenamento jurídico desses institutos participativos.

O Estado, as instâncias políticas e populares almejam, a partir daí uma consolidação nos aspectos democráticos e de participação com amparo jurídico na organização da Administração Pública, que promova uma maior interação entre tais instituições.

\section{PARTICIPAÇÃO POPULAR NA ADMINISTRAÇÃO PÚBLICA}

Os institutos de participação popular na Administração Pública correlacionam-se à concretude democrática e ao Estado de Direito contemporâneo, posto que a transparência na junção das tarefas próprias da função administrativa estatal possui o objetivo de ampliar a realização, segundo Miranda (2003, p. 85) do "status activae civitatis", ou da "cidadania social", que de acordo 
com Dalfino (2005) possibilita uma realização sólida dos direitos políticos e de interferência das pessoas na própria atividade do Estado, bem como na sua formação de vontade. Dessa forma, tais institutos objetivam exercer a democracia nos Estados contemporâneos.

Cabe ressaltar que os institutos de participação popular tornam a Administração Pública mais controlada e constantemente ligada à função de validação dos direitos humanos e/ou essenciais, objetivos fundantes do Estado de Direito em sua concepção material, palpável (GRAU, 2006).

Consequentemente, necessário se faz indagar que, do prisma jurídico, tanto a democracia quanto o Estado de Direito são concepções gerais de Direito Público, e piamente vistos mediante sua ordem constitucional brasileira (PEREZ, 2004).

Podemos então verificar, que tais princípios jurídicos são considerados normativos, que carregam consigo forte grau generalista e de abstração mediante a estruturação essencial de um sistema jurídico (GRAU, 2006). Podemos citar como exemplo, a generalidade instituída pelo artigo 37, caput, da Constituição Federal de 1988, ao definir que a Administração Pública precisa seguir o princípio de tornar públicas suas ações (BRASIL, 1988).

Em ambos, princípio democrático ou princípio do Estado de Direito, a partir de suas inserções na Constituição Federal, tomam para si status muito complexos, devido a passarem a orientar a conduta estatal e da sociedade com indicativos e parâmetros aceitos na atualidade (CANOTILHO, 2003). Explicando melhor, reserva-se do princípio democrático a obrigatoriedade do Estado no que diz respeito às normas da democracia representativa (eleições pré-definidas; nítida separação entre os poderes executivo, legislativo e judiciário; liberdade na escolha de partidos políticos; etc.) e, também implica na estrutura ofertada aos cidadãos para que estes possuam possibilidades de aprendizado dos princípios democráticos, participação efetiva nas decisões, 
formar uma organização do Estado no que tange aos objetivos mor da Administração Pública (PEREZ, 2004).

Dessa forma, fica visível a presença de normas constitucionais que autorizam a elaboração de institutos de participação popular na Administração Pública, mediante princípios da democracia e do Estado de Direito e de organização do Estado Brasileiro regidos pelo artigo $1^{\circ}$ da Constituição Federal (BRASIL, 1988).

\subsection{Participação popular na Administração Pública e a Constituição Federal}

A Constituição Federal de 1988, no intuito de organizar os institutos de participação na Administração Pública, vai muito além da simples citação do princípio democrático e do princípio do Estado de Direito, as funções desses institutos são normatizados com inúmeras normas constitucionais.

Dessa forma fica-nos claro, que muitas prerrogativas legais salientam a participação efetiva nos processos de participação popular na Administração Pública, mas, para além destes artigos existem também medidas e emendas constitucionais que surgiram após a Constituição Federal de 1988, visando uma reforma legal e administrativa no intuito de proporcionar ainda mais tal participação popular.

\subsection{Emenda Constitucional $n^{0} 19$}

A Emenda Constitucional (EC) no 19 alterou a Constituição Federal de 1988, sendo especificamente direcionada a reforma administrativa, instituindo no artigo 37 , parágrafo $3^{\circ}$, uma normativa geral no contexto da participação popular na Administração Pública:

A Lei disciplinará as formas de participação do usuário na administração pública direta e indireta, regulando especialmente:

I- as reclamações relativas à prestação de serviços em geral, asseguradas a manutenção de serviço de atendimento ao usuário e a avaliação periódica, externa e interna da qualidade dos serviços; 
II- o acesso dos usuários a registros administrativos e a informações sobre os atos do governo, observando o disposto no artigo $5^{\circ}$, X e XXXII;

III- a disciplina da representação contra o exercício negligente ou abusivo de cargo, emprego ou função na administração pública (BRASIL, 1995, p. 37).

A EC n ${ }^{\circ} 19$, de alguma maneira, ao colocar as normas acima expostas, promoveu um maior destaque à participação popular da sociedade na Administração Pública, pois, apesar de constar em vários momentos na Constituição Federal referências sobre a participação popular nos mais variados serviços públicos ainda precisavam de um direcionamento que trouxesse à tona disposições gerais da Administração Pública (PEREZ, 2004).

Há de se observar que, uma das prerrogativas inéditas da $\mathrm{EC} \mathrm{n}^{\circ} 19$, que diz respeito à reforma administrativa, foi a inclusão da lista de princípios gerais que regem a Administração Pública no artigo 37 (caput), o princípio da eficiência.

A EC no 19 veio para realçar a importância dos institutos de participação popular na Administração Pública, por meio da alteração do parágrafo $3^{\circ}$, do artigo 37 e por meio da inclusão do princípio da eficiência no aparato do artigo 37, caput, sendo seus objetivos maiores: desburocratizar, dar transparência e promover qualidade na prestação dos serviços públicos; com a participação dos mais variados institutos da sociedade (GRAU, 2006).

A "reforma administrativa" no Brasil, promovida pela EC n 19, não fica muito diferente dos parâmetros adotados por outros países da América Latina, pois, segundo Dromi (2002, p. 144) a reforma na Argentina passou por buscar um novo modelo de Estado, objetivando, por meio da transposição de atividades, concretizar uma “[...] democracia real de plenitude política, econômica e social" [...]. Assim, se tornava uma obrigatoriedade do Estado e da comunidade em geral, todas as tarefas que ambos poderiam se realizadas, consolidando-se, dessa forma, os administrados a iniciativa e a participação efetiva.

\subsection{A Relação entre o Princípio Constitucional e a Participação Popular}


É importante se destacar, que da consolidação de todas as referências demonstradas pela Constituição Federal do Brasil frente à participação popular na Administração Pública e de sua legitimidade congruente aos princípios democráticos do Estado de Direito, retira-se que a participação administrativa, mediante conceitos constitucionais, demonstra muito mais do que um apanhado de normas e parâmetros dispersos de autorização dos institutos de participação em específicas situações, ou seja, vai além, tornando-se um princípio constitucional (MELLO, 2006).

Diante de tais argumentos, podemos inferir que os princípios jurídicos estão repletos de ordenamentos, seja de maneira intrínseca ou extrínseca, ou seja, declarados expressamente pelo constituinte ou legislador, como aparece no artigo 37 da Constituição, ou facilmente interpretada por juristas sobre as normativas que compõe o sistema constitucional e legal (DI PIETRO, 2006).

Di Pietro (2006) complementa ainda que, os princípios gerais do Direito Administrativo surgem como uma inovação da Constituição Federal de 1988, ao mencionar alguns princípios específicos. Sundfeld (2003) salienta que os princípios de Direito Público são implícitos apenas nos textos que normatizam, sendo necessário desvelá-los.

É possível verificar que para além das afirmações dos autores, os princípios jurídicos carregam em sua essência características que amparam a participação popular na Administração Pública nas suas categorias normativas. Segundo Perez (2004, p. 81):

[...] os princípios são normas que se encontram na base da estruturação de um sistema jurídico dos administrados com a Administração. Logo, esta é sua primeira característica: os princípios e normas jurídicas básicas, essenciais ao correto funcionamento e às perfeitas compreensões das instituições jurídicas.

Entende-se, então, que a função estruturadora da participação popular na Administração Pública podem ser subsidiadas pela Constituição, quando se refere as suas funções sociais, ou ainda, às atividades relativas ao bem-estar, serviços essenciais que fornecem a sociedade igualdade 
indispensável ao viver da liberdade, devendo ser elaboradas a partir da adoção dos institutos participativos.

Assim, segundo Canaris (2006), previdência, saúde, educação, preservação do meio ambiente, ou seja, o planejamento e a execução de políticas públicas ligadas à promoção dos direitos humanos ou fundamentais são atividades sempre acompanhadas pela colaboração, participação, ou controle popular, por disposição expressa da Constituição Federal.

Já num segundo plano, há de se ressaltar que os princípios não almejam exclusividade, ou seja, os princípios não atuam sozinhos, originam-se a partir de outros princípios e regras, e, daí se relacionam, dialogam e se comunicam com a mesma sequência jurídica, o mesmo peso e as mesmas medidas. Fala-se, então, de subprincípios (CANARIS, 2006), isto é, princípios que surgem de outros, assim como no Estado de Direito e legalidade.

Dessa forma, percebe-se a importância da participação na Administração Pública para a consolidação do princípio democrático, do Estado de Direito e eficiência administrativa. Essa participação administrativa, constitui-se como um eixo indispensável à idealização plena da democracia, em seu contexto contemporâneo,

[...] e do Estado de Direito; tanto assim que, relembre-se, a participação permeia o exercício de todas as funções estatais (legislação, jurisdição, e administração) e da eficiência administrativa, pois o grau de complexidade da sociedade e das políticas públicas que a Administração necessita implementar, hodiernamente, reclamou o convívio dos seus mecanismos tradicionais de atuação da Administração Pública com os institutos participativos (PEREZ, 2004).

A participação administrativa, dessa forma, deve ser entendida como de princípio implícito na ordem da Constituição do Brasil, correlacionado ao princípio democrático, ao princípio do Estado de Direito e ao princípio da eficiência administrativa. Neste âmbito, seria aceitável a classificação de subprincípio, posto que surge dos princípios democráticos do Estado de Direito e da eficiência administrativa em seu lócus de organização, ou seja, em balanceada medida onde tanto 
a democracia quanto o Estado de Direito e eficiência administrativa do Estado que aceite os institutos de participação popular na Administração Pública (DI PIETRO, 2002).

O princípio da participação popular na Administração Pública, consiste, então, num princípio de organização. Esse princípio refere-se na elaboração de regras formais de partilha de tarefas e tomada de decisões. A participação popular na Administração Pública é, dessa forma, princípio organizacional, devido implicar na construção de estruturas de processos e tomadas de decisões da Administração Pública ou de divisão das ações da Administração e de seus administrados, de maneira a chamar estes últimos a execução de tarefas inerentes às funções administrativas.

Segundo Duarte (2006, p. 118-119):

\begin{abstract}
A generalidade das categorias apontadas de participação administrativa podem ser incluídas no quadro de um denominador comum, referenciável como participação no procedimento ou participação procedimental, em sentido amplo [...]. A definição de uma noção de participação procedimental assim sustentada é uma consequência direta da aplicação de um critério que separa os fenômenos participatórios relativos à organização e funcionamento internos da estrutura administrativa das espécies participatórias que se representam diretamente no exercício da função administrativa.
\end{abstract}

Por fim, cabe ressaltar que os princípios são caracterizados por não vigorarem, sem exceção, podendo entrar em oposição ou em contradição entre si (CANARIS, 2006). Essa característica muito relevante para colocar em debate sobre o assunto que estamos tratando, pois na medida em que a participação popular na Administração Pública representa uma nova forma de atuar, apesar de contraditório, em vista de instrumentos tradicionais de atuação da Administração baseados no formalismo, na legalidade e na estruturação dos processos burocráticos de tomada de decisão administrativa (PEREZ, 2004).

De fato o ordenamento constitucional continua contemplando, explícita e implicitamente, princípios que possam tornar-se, em determinados casos, contraditórios com a adoção de institutos 
de participação popular na Administração Pública, não impede a caracterização da participação administrativa como um verdadeiro princípio.

Dessa forma, a partir da Constituição Federal de 1988, consagrou-se um novo princípio de organização da Administração Pública: o princípio da participação popular. Princípio este que pode ser caracterizado como: implícito, pois não se encontra arrolado no caput do artigo 37 ou em qualquer norma constitucional de forma expressa, mas é desvendado a partir da combinação de diversas normas constitucionais (artigo 37, parágrafo $3^{\circ}$, artigo 10, artigo 29, X, entre outras); derivado (subprincípio), pois conectado a outros princípios constitucionais, notadamente, o princípio do Estado de Direito, o princípio democrático e o princípio da eficiência administrativa e estruturante da atividade da Administração Pública em diversos graus, pois conduz à formação de processos de decisão e de divisão de funções (PEREZ, 2004).

Por fim, segundo Grau (2006) a interação entre a sociedade e o Estado para a condução de políticas públicas, mais do que um bom instrumento para eficiência e legitimidade dessas políticas, é um princípio constitucional, um imperativo repetido e refletido nas normas infraconstitucionais de organização da Administração Pública.

\subsection{A Nova Administração Pública}

Paula (2005) observa que "apesar de ter se desenvolvido no contexto cultural da Inglaterra e dos Estados Unidos, o gerencialismo ou a nova administração, bem como seu modelo de reforma do Estado e de gestão administrativa, se espalhou pela Europa e América Latina". O Brasil, portanto, se insere nessa dinâmica e mesmo não tendo tido um Estado do Bem-Estar Social nos moldes das economias avançadas, uma vez que o Estado Nacional Desenvolvimentista tenha reproduzido muito mais o capital do que a força de trabalho, também se vê diante de uma situação de crise e de críticas ao patrimonialismo, ao autoritarismo e centralismo do Estado brasileiro partindo para a sua reinvenção, para sua redefinição. 
Segundo Bresser Pereira (1996), a administração pública gerencial parte do pressuposto de que já chegamos a um nível cultural e político em que o patrimonialismo está condenado e a democracia é um regime político consolidado. Aos poucos foram-se delineando os contornos da Nova Administração Pública:

1. Descentralização, do ponto de vista político, transferindo recursos e atribuições para os níveis políticos regionais e locais;

2. Descentralização administrativa, através da delegação de autoridade para os administradores públicos transformados em gerentes crescentemente autônomos;

3. Organizações com poucos níveis hierárquicos ao invés de estruturas piramidais;

4. Organizações flexíveis ao invés de unitárias e monolíticas, nas quais as ideias de multiplicidade, de competição administrada e de conflito tenham lugar;

5. Pressuposto da confiança limitada e não da desconfiança total;

6. Controle por resultados, a posteriori, ao invés do controle rígido, passo a passo, dos processos administrativos e,

7. Administração voltada para o atendimento do cidadão, ao invés de autorreferida.

E com as novas reformas, as modernas ferramentas de gestão como qualidade total, planejamento estratégico, downsizing, benchmarking e terceirização invadem as organizações públicas e os projetos dos gestores públicos do momento.

Paula (2005) destaca o enfoque gerencialista nos programas administrativos implementados pelo Mare, ressaltando o Programa de Qualidade e Participação, o Programa de Reestruturação e Qualidade dos Ministérios e a implementação de uma nova política de recursos humanos. A implementação desses programas pressupõe a utilização de outras ferramentas gerencialistas como o Benchmarking e o Ciclo de Melhoria Contínua. 
Nada demais em querer ser moderno, em buscar proporcionar aos cidadãos serviços rápidos, eficientes e de qualidade. Aliás, é fundamental para a sobrevivência, para a inserção e permanência das organizações públicas na sociedade da informação, na sociedade do conhecimento, que elas se reestruturem e que busquem a inovação. Que valorizem os seus funcionários, qualifiquem, motivem e estabeleçam critérios claros e transparentes de ascensão profissional.

São questões fundamentais, sobretudo num Estado carregado pelas disfunções e anomalias do modelo weberiano, que na sua gênese prescreve a racionalidade, a competência, a meritocracia e o profissionalismo. A gravidade da questão se revela, e aí valem as críticas que se fazem aos modelos propostos para o Estado, quando procura-se implementar ferramentas e utilizar arcabouços teóricos desenvolvidos para o setor privado, a despeito de todas as diferenças e especificidades do setor público.

As diferenças existem no tocante à legislação, às questões sociais, às interferências políticas às quais estão sujeitas as organizações públicas, a problemas de descontinuidade administrativa, barreiras culturais, dentre tantas outras, como as estratégias, os objetivos, a motivação e remuneração de seu quadro de pessoal (PAULA, 2005).

De acordo com Marini (1999) o movimento denominado New Public Management (NPM), que, vem sendo traduzido como Nova Gestão Pública ou Nova Gerência Pública ou, ainda, Nova Administração Pública, é, antes de tudo, um âmbito de debate, um diálogo profissional sobre a estrutura, a gestão e o controle da administração pública envolvendo a comunidade acadêmica e funcionários. Como tal, deve-se descartar a tentação de definições formais, concentrando-se o debate na busca de respostas, segundo determinadas circunstâncias, para as questões de como estruturar, gerenciar e controlar os sistemas burocráticos públicos Já numa visão neo-pública, a NGP implica em: reforçar o conceito de cidadania; reforçar valores da coisa pública nos servidores (eficácia, eficiência e ética); reconhecer novos direitos como garantia dos cidadãos; ter como horizonte a satisfação do cidadão (simplificação, redução de tempos, melhoria da qualidade do 
atendimento, como fez a Bahia com o Serviço de Atendimento ao Cidadão (SAC); focar na universalidade e igualdade; incrementar a qualidade e a quantidade de serviços; fazer uma clara delimitação da externalização dos serviços (admitindo, por exemplo, as privatizações, mas a partir de uma prévia discussão sobre o que é e o que não é papel do Estado, e não como iniciativas do tipo Estado mínimo).

Num esforço de síntese, os princípios podem ser agrupados da seguinte forma:

a) Focalização da ação do Estado no cidadão, o que significa o resgate da esfera pública como instrumento do exercício da cidadania. O Estado deve ser entendido como o fórum onde o cidadão exerce a cidadania; todo e qualquer esforço de reforma, portanto, deve ter como objetivos melhorar a qualidade da prestação do serviço público na perspectiva de quem o usa e possibilitar o aprendizado social de cidadania.

b) Reorientação dos mecanismos de controle por resultados, o que significa evoluir de uma lógica baseada tão somente no controle da legalidade e do cumprimento do rito burocrático para uma nova abordagem centrada no alcance de objetivos.

c) Flexibilidade administrativa que permita às instituições e pessoas alcançarem seus objetivos. Seria a outorga da autonomia necessária para o alcance dos resultados. Mas essa flexibilidade não pode ser de uso extensivo e generalizado, deve ser "sob medida". Nem todos os órgãos necessitam da mesma flexibilidade, e ela tem que estar vinculada ao alcance dos resultados. O contrato de gestão pode ser um útil instrumento de vinculação da flexibilidade a resultados.

d) Controle social, o que quer dizer desenhar mecanismos de prestação social de contas e avaliação de desempenho próximos da ação. Se o objetivo é o resgate da cidadania e a reorientação para resultados, este controle não pode se limitar apenas à dimensão interna, com base em quem presta o serviço. Tem que ser na perspectiva de quem usa ou se beneficia da prestação dos serviços públicos. 
e) Valorização do servidor, que representa, na verdade, a âncora do processo de construção coletiva do novo paradigma orientado para o cidadão e realizado pelo conjunto dos servidores de forma participativa. Implantar uma nova gestão pública não significa mudar sistemas, organizações e legislação; muito mais do que isso, significa criar as condições objetivas de desenvolvimento das pessoas que conduzirão e realizarão as reformas.

Nesse sentido, valorizar o servidor quer dizer estimular sua capacidade empreendedora, sua criatividade, destacando o espírito público de sua missão e o seu comportamento ético, visando ao resgate da autoestima e ao estabelecimento de relações profissionais de trabalho (MARINI, 1999).

Segundo Gomes (2007), Estado e o mercado, sozinhos, parecem sem condições de enfrentar a crise econômica, social e ambiental em que as sociedades estão mergulhadas e de resolver os desafios colocados pelos novos tempos. Nesse contexto, a sociedade civil está sendo chamada, cada vez mais, para formular alternativas.

As constatações acima nos levam a reafirmar alguns dos princípios básicos da agenda atual no que diz respeito às questões do Estado e da gestão pública, tais como: a focalização no cidadão, a transparência, o controle social, a conscientização da responsabilidade fiscal, a orientação da gestão para resultados, a ética e a profissionalização do servidor público.

Dessa forma, e concordando com Marini (1999) o grande desafio é o de assegurar a irreversibilidade do processo de transformação, a partir do fortalecimento das iniciativas bem-sucedidas e do realinhamento que se fizer necessário para incorporação dos temas emergentes.

\section{CONSIDERAÇÕES FINAIS}

Neste trabalho levantamos questões referente a Participação Popular e sua relação com a Administração Pública, seu histórico, desenvolvimento e possibilidades. Enquanto aos objetivos almejados, debatemos sobre os institutos jurídicos que asseguram a participação popular na 
Administração Pública, mas não somente de doutrina jurídica, mas multidisciplinar, com lócus voltado às discussões da ciência administrativa, ciência política e sociológica, mas também, à suas relações

Ao finalizarmos, verificamos que a participação popular no âmbito da Administração Pública pode promover uma estruturação democrática por meio de processos que envolvem diálogos e decisões mútuas entre os cidadãos e a Administração Pública, visando assim o aumento no nível de eficiência e eficácia dos serviços por ela prestados.

Há de se enfatizar que no Brasil, por meio da Constituição Federal e suas Emendas existem artifícios que permitem que os processos e princípios de participação da sociedade se concretizem através dos institutos de participação pública.

Para além da eficiência dos serviços públicos, é notório perceber que a participação popular pode (ou deve) se dar norteados pela legitimidade, onde o Direito Constitucional e suas interpretações devem acontecer de maneira clara e minimizar os entraves dos princípios básicos da participação efetiva da sociedade na Administração Pública.

A relação entre sociedade e Administração Pública, na atualidade, não deve ser mais encarada como uma relação tutelada onde o Estado dita as regras e desenvolve os serviços públicos e a população fica sob sua responsabilidade, sem diálogo, sem questionamentos, e à mercê da uma eficiência (ou deficiência) dos serviços proporcionados.

A participação popular na Administração Pública rompe com dogmas e paradigmas tradicionais que por décadas estiveram presentes na vida dos cidadãos. Surge, então, como forma de ultrapassar barreiras para a construção conjunta de relações para o impulsionamento e a atuação da sociedade para/sobre ela mesma gerando um arcabouço de Estado de Bem-Estar, e auto afirmando a legitimidade dos institutos de participação popular na Administração dos serviços públicos, principalmente os essenciais: Educação, Serviços Social, Segurança, dentre outros. 
Por fim, percebemos que por meio de uma maior participação efetiva da sociedade centrada no funcionamento eficaz da Administração Pública proporciona uma legitimidade e aproximação dos interesses gerais da população, bem como norteiam uma concretização de políticas públicas e/ou programas estatais demonstrando maior clareza nos aspectos de seu desenvolvimento, ampliando as dimensões do Bem-Estar coletivo e justiça social e transparência da próprias atuação na administração dos recursos de cunho político, econômico e social.

\section{REFERÊNCIAS}

BRASIL. Emenda constitucional $\mathbf{n}^{\circ}$ 19, de 04 de junho de 1998. Modifica o regime e dispõe sobre princípios e normas da Administração Pública, servidores e agentes políticos, controle de despesas e finanças públicas e custeio de atividades a cargo do Distrito Federal, e dá outras providências.

BRASIL. Plano diretor da reforma do aparelho do estado. Brasília: Presidência da república, Câmara da Reforma do Estado, Ministério da Administração Federal e Reforma do Estado, 1995.

BOBBIO, Norberto. O futuro da democracia. São Paulo: Paz e Terra, 1996

. A era dos direitos. $7^{\mathrm{a}}$ ed.Rio de Janeiro: Campus, 2012.

BURDEAR, Georges; HAMON, Francis; TROPER, Michel. $5^{\text {a }}$ ed. Direito constitucional. Paris: LGDJ, 2005.

CANARIS, Claus-Wilheim. Pensamento sistemático e conceito de sistema na ciência do direito. 10a ed.Lisboa: Fundação Calouste Gulbenkian, 2006.

CANOTILHO, J. J. Gomes. Direito constitucional. $7^{\text {a }}$ ed. Coimbra: Almedina, 2003.

CHEVALLIER, Jacques. Ciência administrativa. 6 $6^{\text {a }}$ ed. Paris: PUF, 2004.

BENEVIDES, Maria Victoria de Mesquita. A cidadania ativa. $3^{\text {a }}$ ed. São Paulo: Ática, 2006.

DAHL, Robert A. Poliarquia: Participação e Oposição. São Paulo: Editora da Universidade de São Paulo, 1997.

DALLARI, Dalmo de Abreu. O que é participação política. São Paulo: Brasiliense, 1995.

DALBERIO, Osvaldo; DALBERIO, Maria Célia Borges. Metodologia Científica: desafios e caminhos. São Paulo: Paulus, 2009.

DALFINO, Enrico. Basi per dirittio. In.: AMOROSINO, Sandro (org.). A transformação do direito administrativo. Milão: Giuffré, 2005.

DI PIETRO, Maria Sylvia Zanella. Participação Popular na Administração. São Paulo: RTDP, 2003.

Direito administrativo. $4^{\mathrm{a}}$ ed. São Paulo: Atlas, 2006.

DROMI, José Roberto. Derecho administrativo. $6^{a}$ ed. Tradução nossa. Buenos Aires: Astrea, 2002. 
FARIA, José Eduardo. A crise constitucional e a restauração da legitimidade. $6^{\text {a }}$ ed.Porto Alegra: Fabris, 2005.

FERREIRA FILHO, Manoel Gonçalves. A democracia possível. $5^{\text {a }}$ ed.São Paulo: Saraiva, 2002. . Constituição e governabilidade. $4^{\mathrm{a}}$ ed. São Paulo: Saraiva, 2005.

GRAU, Eros Roberto. O direito posto e o direito pressuposto. $4^{\text {a }}$ ed. São Paulo: Malheiros, 2006.

HABERMAS, Jürgen. Direito e democracia: entre facticidade e validade. v. I. 2 ed. Trad. Flávio Beno Siebeneichler. Rio de Janeiro: Tempo Brasileiro, 2012

HELD, David. Modelos de democracia. 6a ed. Belo Horizonte: Paidéia, 2007.

HOBSBAWM, Eric. A era dos extremos. São Paulo: Cia das Letras, 2006.

LINCOLN, Abraham. Great speeches. 4ª ed. Nova York, Dover, 2001.

MARINI, Caio. Crise e Reforma do Estado: uma questão de cidadania e valorização do servidor In: Petrucci, Vera e Schwarz, Letícia. Administração pública gerencial: a reforma gerencial de 1995

- Ensaios sobre a reforma administrativa brasileira no limiar do Século XXI. Brasília: Editora UNB, 1999.

MEDAUR, Celso Antônio Bandeira de. Curso de direito administrativo. $4^{\mathrm{a}}$ ed. São Paulo: Malheiros, 1996.

MEIRELLES, Hely Lopes. Direito administrativo brasileiro. São Paulo: Malheiros, 2004.

MIRANDA, Jorge. Manual de direito constitucional. $7^{\text {a }}$ ed. Coimbra: Coimbra, 2003.

MORAIS, Ricardo Manoel Oliveira; SILVA, Adriana Campos. O liberalismo econômico e as práticas de segurança: o "avesso" das democracias liberais. Revista da Faculdade de Direito UFPR, Curitiba, PR, Brasil, v. 62, n. 3, p. 221-242, set./dez. 2017.

OLIVEIRA, SANDRO. TORRES, Kelly Aparecida. BORBA, Érika Loureiro. MENDONÇA, Fabricio Molica de. MARTINS, Pablo. L. O Uso do Sistema Registro de Preços nas Contratações Públicas: Um Estudo de Caso. Revista Científica Semana Acadêmica. Fortaleza, ano MMXIX, No. 000176, 14/08/2019. Disponível em:

https://semanaacademica.org.br/artigo/o-uso-do-sistema-registro-de-precos-nas-contratacoes-public as-um-estudo-de-caso Acessado em: 23/07/2020.

PAUlA, Ana Paula Paes de. Por uma Nova Gestão Pública. São Paulo: FGV Editora, 2005.

PEREIRA, Leandro Ramos; ALMEIDA, Rodrigo Bonecini de. A utopia keynesiana: os princípios políticos e econômicos de John Maynard Keynes. ANPEC, 2010.

PEREZ, Marcos Augusto. A administração pública democrática. Belo Horizonte: Fórum, 2004.

RAWLS, John. Justiça e democracia. São Paulo: Seuil, 2006.

SARTORI, Giovanni. A teoria da democracia revisitada. 3ª ed. São Paulo: Ática, 2004.

SCHMITT, Carl. Teoría de La Constitución. Presentación de Francisco Ayala. Primera edición em “Alianza Universidad Textos” 1982. Cuarta reimpresión em "Alianza Universidad Textos". Madrid. España. 2003.

SILVA, José Afonso da. Curso de direito constitucional positivo. São Paulo: Revista Tribunais, 2010. 
SUNDFELD, Carlos Ari. Fundamentos de direito público. São Paulo: Malheiros, 1993. 